\section{(6) OPEN ACCESS}

\title{
The effects of tocilizumab on osteitis, synovitis and erosion progression in rheumatoid arthritis: results from the ACT-RAY MRI substudy
}

\author{
Philip G Conaghan, ${ }^{1}$ Charles Peterfy, ${ }^{2}$ Ewa Olech, ${ }^{3}$ Jeffrey Kaine, ${ }^{4}$ David Ridley, ${ }^{5}$ \\ Julie DiCarlo, ${ }^{2}$ Josh Friedman, ${ }^{6}$ Jenny Devenport, ${ }^{6}$ Orrin Troum $^{7}$
}

\begin{abstract}
Handling editor Tore K Kvien
- Additional material is published online only. To view please visit the journal online (http://dx.doi.org/10.1136/ annrheumdis-2013-204762).

1 University of Leeds \& NIHR Leeds Musculoskeletal Biomedical Research Unit, Leeds, UK

${ }^{2}$ Spire Sciences, Inc, Boca Raton, Florida, USA ${ }^{3}$ University of Nevada School of Medicine, Las Vegas, Nevada, USA

${ }^{4}$ Sarasota Arthritis Center, Sarasota, Florida, USA ${ }^{5}$ Saint Paul Rheumatology, Eagan, Minnesota, USA ${ }^{6}$ Genentech, Inc, South San Francisco, California, USA ${ }^{7}$ University of Southern California, Santa Monica, California, USA
\end{abstract}

\section{Correspondence to} Professor Philip G Conaghan, Leeds Institute of Rheumatic and Musculoskeletal Medicine, Chapel Allerton Hospital, Chapeltown Road, Leeds, LS7 4SA, UK; p.conaghan@leeds.ac.uk

Received 15 October 2013 Revised 8 January 2014 Accepted 24 January 2014 Published Online First 13 February 2014

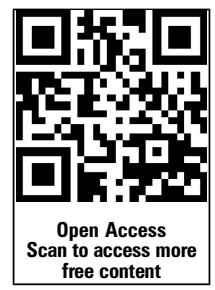

\section{SLinked}

- http://dx.doi.org/10.1136/ annrheumdis-2013-204761

To cite: Conaghan $\mathrm{PG}$, Peterfy C, Olech E, et al. Ann Rheum Dis 2014;73:810-816.

\section{ABSTRACT}

Objective To examine the imaging-detected mechanism of reduction of structural joint damage progression by tocilizumab (TCZ) in patients with rheumatoid arthritis (RA) using MRI.

Methods In a substudy of a randomised, double-blind, phase $3 \mathrm{~b}$ study (ACT-RAY) of biologic-naïve patients with RA who were methotrexate (MTX)-inadequate responders, 63 patients were randomised to continue MTX or receive placebo (PBO), both in combination with TCZ $8 \mathrm{mg} / \mathrm{kg}$ every 4 weeks, with optional additional disease-modifying antirheumatic drugs at week 24 if Disease Activity Score of 28 joints $<3.2$. The most symptomatic hand was imaged with 0.2 Tesla extremity MRI at weeks 0, 2, 12 and 52. MR images were scored using Outcome Measures in Rheumatology-Rheumatoid Arthritis Magnetic Resonance Imaging Score. Predictors of week 52 erosion progression were determined by logistic regression analysis.

Results TCZ + PBO ( $n=32)$ demonstrated mean improvements in synovitis from baseline to weeks $2(-0.92 ; p=0.0011), 12(-1.86 ; p<0.0001)$ and 52 (-3.35; $p<0.0001)$, while TCZ + MTX ( $n=31)$ had mean improvements in synovitis at week $12(-0.88$; $p=0.0074)$, but not week $52(-1.00 ; p=0.0711)$. $\mathrm{TCZ}+\mathrm{PBO}$ demonstrated mean reductions in osteitis at weeks $12(-5.10 ; p=0.0022)$ and $52(-8.56$; $\mathrm{p}=0.0006)$, while $\mathrm{TCZ}+\mathrm{MTX}$ had mean reductions at weeks $2(-0.21 ; p<0.05)$ and $12(-3.63 ; p=0.0008)$, but not week $52(-2.31 ; p=0.9749)$. Mean erosion scores did not worsen in either group. MRI erosion scores at weeks 12 and 52 correlated strongly with radiography erosion scores at week 52 ( $r>0.80)$. Baseline synovitis and worsening of osteitis predicted erosion progression.

Conclusions Rapid suppression of synovitis and osteitis with reduction in structural joint damage progression occurred with $\mathrm{TCZ}$, as monotherapy or in combination with MTX, through week 52.

\section{INTRODUCTION}

Conventional radiographs have traditionally been used to detect structural damage, signs of bone erosion and joint space narrowing in rheumatoid arthritis (RA). MRI-a more sensitive and specific technique than clinical examination or plain film radiography_can measure inflammation in the synovium (synovitis) and bone marrow (osteitis) as well as structural damage. ${ }^{12}$ Both synovitis and osteitis play a central role in the pathogenesis of RA and predict radiographic progression. ${ }^{3-5}$ Importantly, subclinical disease is common even in patients with RA who have achieved remission based on a Disease Activity Score of 28 joints (DAS28). Some studies have demonstrated that $30 \%$ of patients in remission had radiographic progression, $96 \%$ had synovitis and $35 \%$ had osteitis. ${ }^{6} 7$ MRI therefore enables a more sensitive assessment of disease activity, detection of early markers of disease progression and provides a sensitive measure of therapeutic response. ${ }^{89}$

Tocilizumab (TCZ) is a recombinant humanised anti-interleukin-6 receptor (IL-6R) monoclonal antibody that blocks IL-6 from binding to soluble and membrane-bound IL-6R. The efficacy and safety of TCZ monotherapy and TCZ in combination with disease-modifying antirheumatic drugs (DMARDs) were shown in adult patients with RA in five pivotal phase 3 clinical trials. ${ }^{10-14}$ Treatment of patients with TCZ also inhibited progression of radiographic joint damage as measured by $\mathrm{X}$-ray within 6 months of treatment initiation. ${ }^{13}$ However, there are limited data on the tissue-level effects of TCZ.

In a large, randomised, phase $3 \mathrm{~b}$ study (ACT-RAY), both TCZ treatment strategies showed improvements in signs and symptoms over time, although TCZ in combination with methotrexate (TCZ+MTX; add-on strategy) did not show statistical superiority over TCZ as monotherapy (TCZ + placebo (PBO); switch strategy) on the primary endpoint (week 24 DAS28 remission) and several other assessments. At week 52, there were statistically significant differences between groups on 4 of the 19 endpoints. ${ }^{15}$ The ACT-RAY study further showed that both treatment strategies with TCZ can prevent radiographic progression in most patients. The aim of this MRI substudy within ACT-RAY was to evaluate the effects of TCZ treatment, with and without MTX, on imaging markers of inflammation (synovitis and osteitis), and erosion progression.

\section{PATIENTS AND METHODS}

\section{Study design}

The patients and methods from the main study were described previously. ${ }^{16}$ ACT-RAY was a global, 3-year, randomised, double-blind, placebocontrolled, phase $3 \mathrm{~b}$ study $(\mathrm{N}=553)$. Patients aged $\geq 18$ years with RA, according to the revised 1987 American College of Rheumatology criteria, were included if they had $\geq 1$ radiographic erosion. 
Patients were required to have active disease and to have had an inadequate response to MTX (defined as a DAS28 of $>4.4$ at baseline). Patients were excluded if they had been previously treated with a biological agent. This preplanned substudy performed in the USA included 63 patients from 18 sites.

Eligible patients were randomised at baseline using a minimisation algorithm that was stratified by site and baseline DAS28 based on erythrocyte sedimentation rate (ESR) $(\leq$ or $>5.5$ ). From baseline to week 24 , eligible patients were randomised to receive open-label TCZ $8 \mathrm{mg} / \mathrm{kg}$ intravenously every 4 weeks in combination with either MTX (TCZ+MTX) or PBO (TCZ+PBO). From weeks 24 to 52, patients continued with TCZ therapy with blinded MTX or PBO, but open-label conventional (ie, non-biologic) DMARDs could be added, based on disease activity (DAS28>3.2), with the objective of inducing clinical remission (DAS28<2.6).

\section{Outcomes and assessments}

The most symptomatic hand and wrist of each patient were scanned with a 0.2 Tesla (T) extremity MRI system at weeks 0 (baseline), 2, 12 and 52. Reproducible positioning was ensured with a specially designed acrylic hand frame. ${ }^{17}$ Anatomic coverage extended from the distal radioulnar joint proximally to the proximal interphalangeal joints distally and included the entire thumb. The joints of the hands were scanned separately from those of the wrist. The Outcome Measures in RheumatologyRheumatoid Arthritis Magnetic Resonance Imaging Score (OMERACT-RAMRIS) was used to assess synovitis, osteitis and erosion using a modification that included the first metacarpophalangeal (MCP) joint. ${ }^{18}$ Synovitis was assessed in eight regions of the hand and wrist, and each region was scored from 0 to 3 (normal or proportion of volume of estimated maximally distended synovial cavity, in thirds) for a total score of 0-24. Osteitis was assessed in 25 regions in the hand and wrist, and each region was scored from 0 to 3 (normal or proportion of involvement of estimated original, non-eroded bone, in thirds) for a total score of $0-75$. Erosions were evaluated in 25 regions in the hand and wrist, and each region was scored from 0 to 10 (normal or by deciles of percentage of articular bone eroded) for a total score of 0-250. No gadolinium enhancement was used.

All MR images were quality controlled and scored independently by two radiologists blinded to treatment assignment and visit order. For the $5 \%$ of patients in each category (synovitis, osteitis and erosion) with the largest inter-reader change-score discrepancies, adjudicated values for the blinded visits were determined by consensus. Unless an adjudicated value was present (in which case that value was used), the average value at each visit of the MRI readings from the two readers was used in the analyses. The endpoints of interest for analysis were change from baseline in MRI-measured synovitis, osteitis and erosion scores at weeks 0 (baseline), 2, 12 and 52.

Radiographs of hands/wrists and feet were obtained at baseline, week 24 and week 52 using a standardised technique. All radiographs collected in the ACT-RAY study, including those in this substudy, were assessed using the Genant-modified Total Sharp Score (mTSS) by two independent readers who were blinded to treatment assignment and visit order. Clinical measures-including DAS28, the Health Assessment Questionnaire, tender joint count, swollen joint count and adverse eventswere also collected at baseline and every 4 weeks thereafter.

\section{Statistical methods}

Sample size was estimated based on a previous study in which a reduction in synovitis of 2.1 was detected in patients who received infliximab+MTX and of 0.3 for the $\mathrm{PBO}+\mathrm{MTX}$ comparator group $(\mathrm{p}<0.05) .{ }^{19}$ From this information, a common SD of 2.0 was derived. A sample size of 60 patients (30 in each treatment group) would provide at least $80 \%$ power to detect a difference between groups with the use of a two-sample t test, assuming an effect size of 0.9 , a type 1 error of $5 \%$ and oversampling adjustment for a $20 \%$ dropout rate.

Descriptive statistics were used to evaluate the demographic, disease and joint damage characteristics between groups at baseline and to summarise observed scores and changes from baseline scores for MRI and disease activity over time. The $p$ values for within-group MRI changes from baseline scores were estimated based on the Wilcoxon signed-rank test of the hypothesis of no change from baseline. Cumulative probability plots were produced to visualise differences between groups in changes in MRI scores from baseline to week 52. To provide additional context for interpreting analyses of progression, the smallest detectable change (SDC) was calculated to differentiate true change from inter-reader variability. ${ }^{20}$ Finally, logistic regressions with generalised estimating equations were used to evaluate associations between joint-level MRI erosion progression at week 52 and baseline synovitis and osteitis scores as well as changes in synovitis and osteitis in matching joints, with adjustment for the correlation of joints within patients to produce ORs with 95\% CIs and $\mathrm{p}$ values. One model estimated joint-level erosion progression at week 52 from assessments at earlier time points: baseline levels of synovitis and osteitis as well as changes in synovitis and osteitis to week 12. A second model estimated joint-level erosion progression at week 52 from assessments at baseline and concurrent time points: baseline levels of synovitis and osteitis and change in synovitis and osteitis to week 52. Analyses were performed in the modified intent-to-treat population (defined as all patients randomised in the study who received at least one dose of TCZ and who had baseline and postbaseline synovitis, osteitis or bone erosion scores in the wrist or in 1-5 MCP joints) and were based on observed data with no imputation for missing data.

\section{RESULTS}

\section{Patient disposition and baseline characteristics}

Of the 113 patients screened, 63 were randomised: 31 received $\mathrm{TCZ}+\mathrm{MTX}$ and 32 received $\mathrm{TCZ}+\mathrm{PBO}$ (figure 1). The predominant reason for screening failure $(>50 \%)$ was no evidence of radiographic erosion at screening.

A total of $74 \%$ of patients in the TCZ+MTX group and $75 \%$ of patients in the TCZ+PBO group completed 52 weeks of the study. Eight patients withdrew from each group, most commonly for non-safety reasons. Baseline demographic and clinical characteristics of the patients were balanced across the $\mathrm{TCZ}+\mathrm{MTX}$ and TCZ+PBO groups (table 1). Baseline RAMRIS scores reflected high-disease severity for the TCZ+MTX and TCZ+PBO groups. Radiographic scores (mTSS, joint space narrowing and erosion) were also similar between the groups.

\section{Imaging findings}

Patients in both treatment arms had statistically significant improvements in synovitis over time (figure 2A). As with clinical signs and symptoms, numeric differences were observed between groups; larger mean improvements were observed in the TCZ+PBO group versus the TCZ+MTX group. The cumulative distribution plot of change in total synovitis from baseline to week 52 also showed that more patients in the $\mathrm{TCZ}+\mathrm{PBO}$ group had improvements greater than the SDC. 


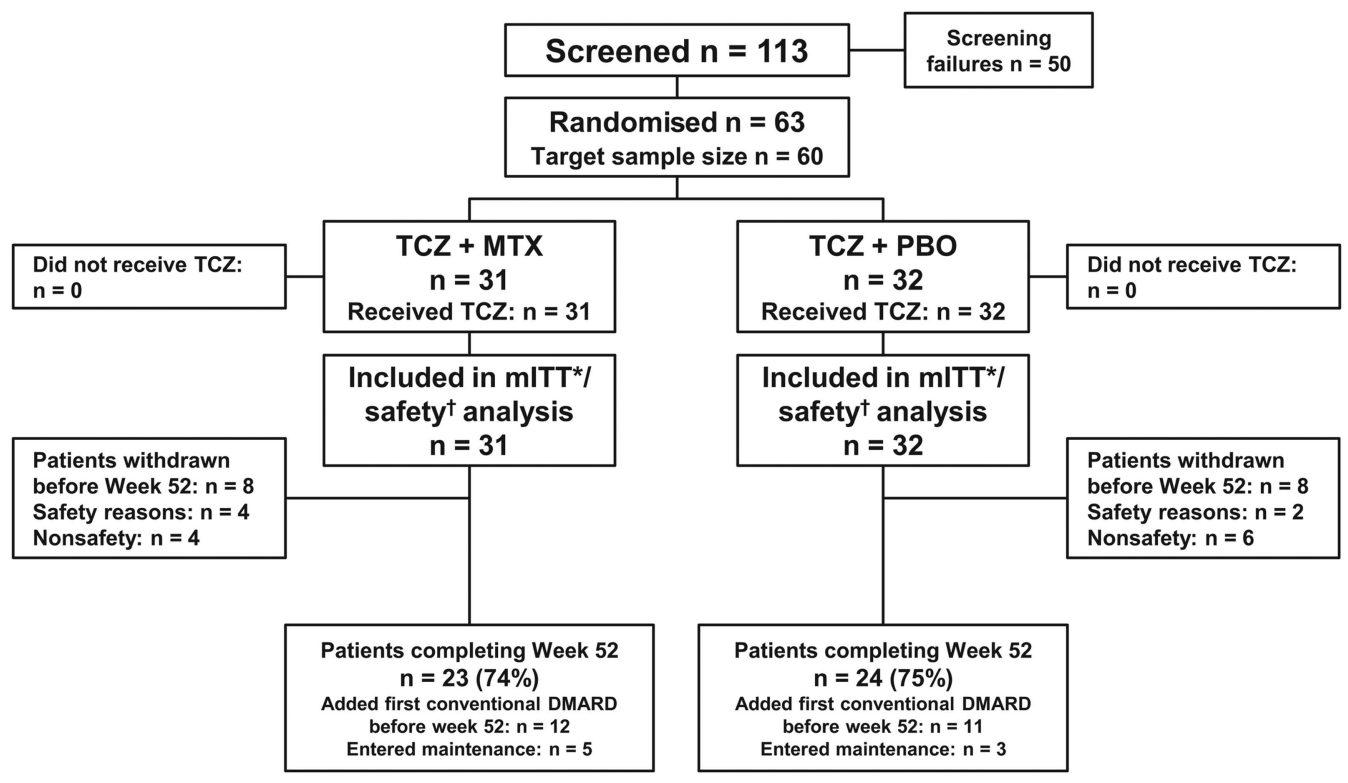

" $\mathrm{mITT}$ consisted of all patients randomised in the study who received at least 1 dose of TCZ and who had baseline and postbaseline synovitis, bone edema, or bone erosion scores in the wrist or in 1 to 5 metacarpophalangeal joints.

t Safety analyses include all patients who received at least one dose of TCZ.

Figure 1 Patient disposition. DMARD, disease-modifying antirheumatic drug; mITT, modified intent-to-treat; MTX, methotrexate; PBO, placebo; TCZ, tocilizumab.

Table 1 Baseline demographics and clinical, MRI and radiographic characteristics

\begin{tabular}{|c|c|c|}
\hline & $\begin{array}{l}\mathrm{TCZ}+\mathrm{MTX} \\
(\mathrm{N}=31)\end{array}$ & $\begin{array}{l}\mathrm{TCZ}+\mathrm{PBO} \\
(\mathrm{N}=32)\end{array}$ \\
\hline \multicolumn{3}{|l|}{ Demographics and clinical characteristics } \\
\hline Female, $\mathrm{n}(\%)$ & $24(77.4)$ & $21(65.6)$ \\
\hline Age, mean (SD), year & $55.2(14.12)$ & $55.8(10.46)$ \\
\hline Disease duration, mean (SD), year & $7.8(7.23)$ & $6.5(8.07)$ \\
\hline \multicolumn{3}{|l|}{ Disease duration, n (\%) } \\
\hline$<2$ years & $10(32.3)$ & $13(40.6)$ \\
\hline$\geq 2$ to $<5$ years & $4(12.9)$ & $7(21.9)$ \\
\hline$\geq 5$ to $<10$ years & $6(19.4)$ & $4(12.5)$ \\
\hline$\geq 10$ years & $11(35.5)$ & $8(25.0)$ \\
\hline Oral steroids, n (\%) & $15(48.4)$ & $13(40.6)$ \\
\hline No. of previous DMARDs, mean (SD) & $1.5(1.18)$ & $1.5(0.62)$ \\
\hline CRP, mean (SD), mg/dL & $1.1(1.38)$ & $1.3(1.88)$ \\
\hline DAS28, mean (SD) & $6.4(1.0)$ & $6.5(1.1)$ \\
\hline \multicolumn{3}{|l|}{ MRI, n (\%) } \\
\hline Synovitis present, n (\%) & $31(100)$ & $32(100)$ \\
\hline Osteitis present, n (\%) & $22(71)$ & $24(75)$ \\
\hline Erosion present, $\mathrm{n}(\%)$ & $31(100)$ & $32(100)$ \\
\hline \multicolumn{3}{|l|}{ Modified RAMRIS, mean (SD) } \\
\hline Synovitis & $7.23(4.604)$ & $7.42(4.164)$ \\
\hline Osteitis & $7.77(12.261)$ & $11.06(14.800)$ \\
\hline Erosion & $19.37(14.440)$ & $15.97(12.558)$ \\
\hline \multicolumn{3}{|l|}{ X-ray, mean (SD) } \\
\hline Total mTSS, mean (SD) & $21.23(25.475)$ & $19.01(24.988)$ \\
\hline Joint space narrowing, mean (SD) & $10.48(13.701)$ & $7.94(12.198)$ \\
\hline Erosion, mean (SD) & $10.76(12.202)$ & $11.07(13.993)$ \\
\hline
\end{tabular}

Statistically significant improvements in mean change from baseline in osteitis were observed at weeks 12 and 52 in the TCZ+PBO group and at weeks 2 and 12 in the TCZ+MTX group (figure $2 \mathrm{~B}$ ). The cumulative distribution plot of the change from baseline in the total osteitis score at week 52 showed that more patients in the TCZ $+\mathrm{PBO}$ group had improvements in osteitis greater than the SDC, whereas the majority of patients in the TCZ+MTX group had no change relative to the SDC.

Mean RAMRIS erosion scores did not statistically significantly worsen in either group over 52 weeks of treatment (figure 2C). The cumulative distribution plots of change from baseline in total erosion scores at week 52 were similar and overlapped in the TCZ+MTX and TCZ+PBO groups; most patients showed no progression of erosion.

A small but statistically significant mean change (worsening) in radiographic mTSS scores from baseline to week 52 was observed in patients who received TCZ+MTX (mean (SD) change, 0.27 (0.612); $p=0.0434$ ) (see online supplemental figure $1 \mathrm{~A})$. In the $\mathrm{TCZ}+\mathrm{PBO}$ group, the mean (SD) change from baseline to week 52 in mTSS scores was $0.08(0.808$; $\mathrm{p}=0.3484)$. The mean (SD) change from baseline to week 52 in the radiographic erosion score was $-0.02(0.333)$ for patients who received TCZ+MTX and 0.05 (0.65) for patients who received $\mathrm{TCZ}+\mathrm{PBO}$ (see online supplemental figure $1 \mathrm{~B}$ ). The mean (SD) change from baseline to week 52 in joint space narrowing was $0.28(0.72)$ for patients who received TCZ+MTX and $0.04(0.20)$ for patients who received TCZ+PBO (see online supplemental figure $1 \mathrm{C}$ ).

In the TCZ+MTX group, radiographic erosion scores at week 52 were highly correlated with MRI erosion scores at weeks $12(\mathrm{r}=0.88 ; \mathrm{p}<0.0001)$ and $52(\mathrm{r}=0.83 ; \mathrm{p}<0.0001)$ (figure 3). Similar results were observed in the $\mathrm{TCZ}+\mathrm{PBO}$ group, in which radiographic erosion scores at week 52 were 
A

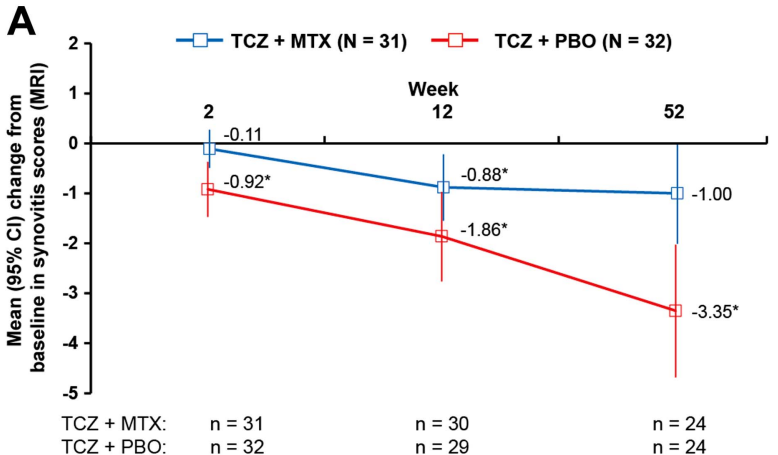

${ }^{\star} P<0.05$ when compared with baseline.

B

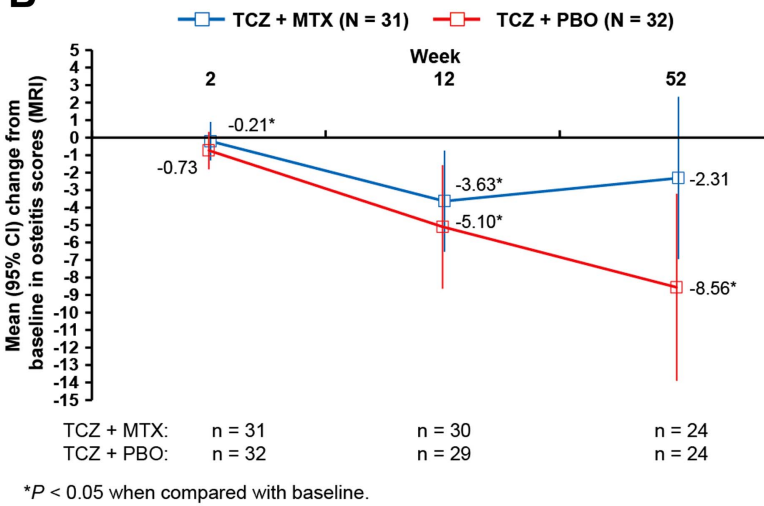

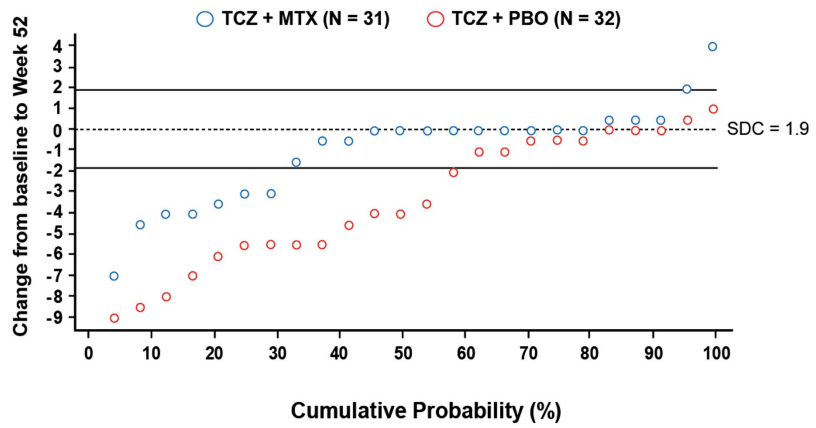

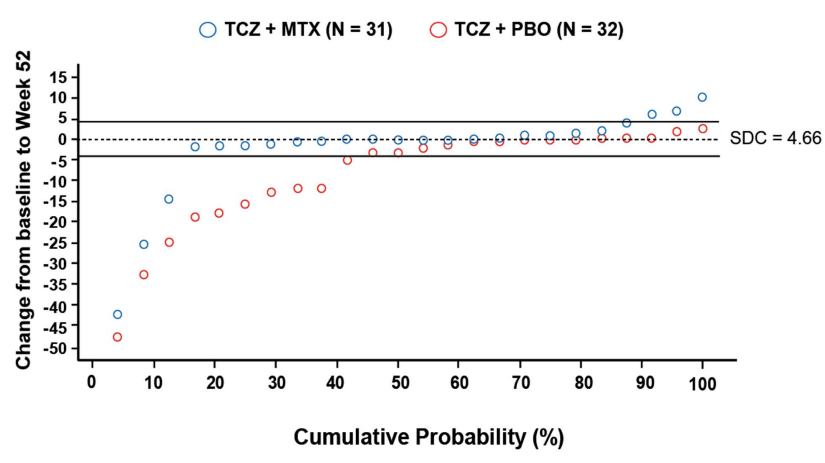

Cumulative Probability (\%)

C
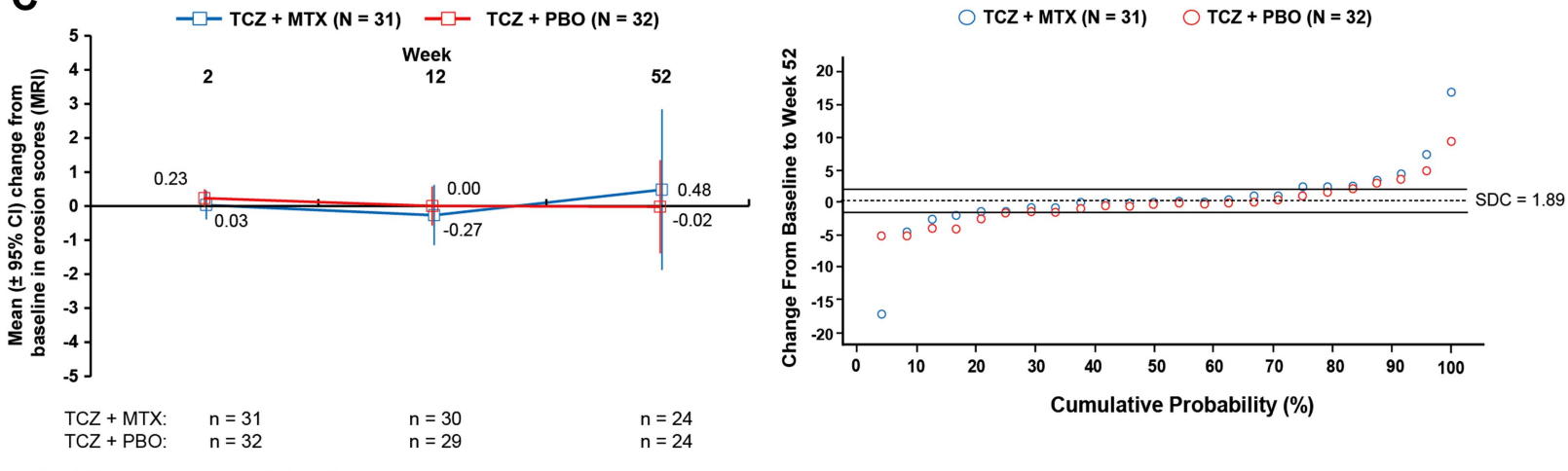

${ }^{*} P<0.05$ when compared with baseline.

Figure 2 Changes in MRI scores in patients taking tocilizumab (TCZ) $8 \mathrm{mg} / \mathrm{kg}$ plus methotrexate (MTX) or placebo (PBO) plus MTX. (A) Mean change from baseline in synovitis scores over 52 weeks and cumulative distribution plot of the mean change from baseline in synovitis scores at week 52. (B) Mean change from baseline in osteitis scores over 52 weeks and cumulative distribution plot of the mean change from baseline in osteitis scores at week 52. (C) Mean change from baseline in erosion scores over 52 weeks and cumulative distribution plot of the mean change from baseline in erosion scores at week 52. Synovitis scores could range from 0 to 24 . Osteitis scores could range from 0 to 75 . Erosions scores could range from 0 to 250. $p$ Value is from the within-group Wilcoxon signed-rank test of the hypothesis of no change from baseline. SDC, smallest detectable change.

also highly correlated with MRI erosion scores at weeks 12 $(\mathrm{r}=0.83 ; \mathrm{p}<0.0001)$ and $52(\mathrm{r}=0.80 ; \mathrm{p}<0.0001)$.

\section{Association between early synovitis and osteitis and MRI erosion progression at week 52}

The statistical models fit to evaluate joint-level MRI erosion progression at week 52 from baseline and changes in synovitis and osteitis are presented in table 2. For the first model, baseline synovitis and worsening from baseline to week 12 in osteitis were statistically significantly associated with erosion progression in the same joint at week 52. Similarly, for the second model, baseline synovitis and worsening from baseline to week 52 in osteitis were statistically significantly associated with erosion progression in the same joint at week 52 .

\section{Clinical efficacy}

As shown in figure 4, means for DAS28 over time were generally similar between treatment groups, although there were numeric differences at week 52 (mean (SD): TCZ+MTX, 3.37 (0.31); TCZ+PBO, $2.49(0.24))$. The mean (SD) change from baseline to 52 weeks in the swollen joint count was -13.40 (10.54) in the TCZ+MTX group and -16.38 (11.49) in the 
Figure 3 Correlation between radiographic erosion scores at 52 weeks and MRI erosion scores at weeks 12 and 52 . MTX, methotrexate; PBO, placebo; TCZ, tocilizumab.

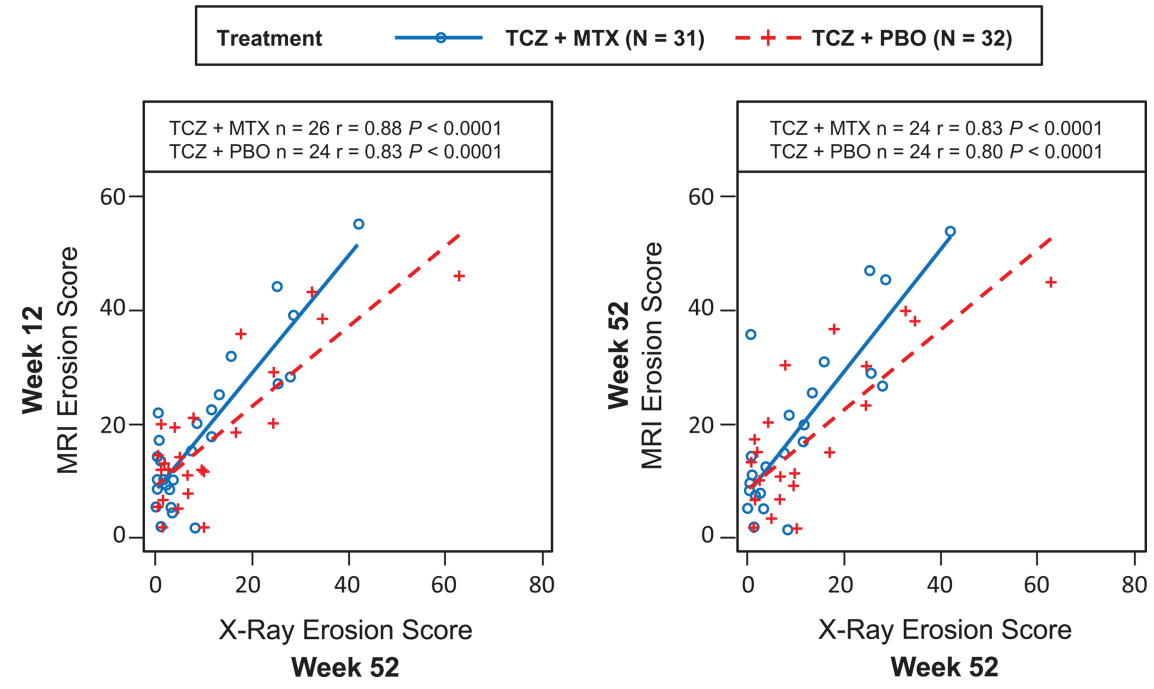

$\mathrm{TCZ}+\mathrm{PBO}$ group. The mean (SD) change from baseline to 52 weeks in the tender joint count was $-15.32(17.76)$ in the TCZ+MTX group and $-21.00(12.98)$ in the TCZ+PBO group.

\section{DISCUSSION}

The ACT-RAY MRI substudy used MRI to directly measure synovitis, osteitis and erosion in response to TCZ and confirmed that treatment with TCZ rapidly reduces joint synovitis and osteitis in patients with RA. Early suppression of synovitis and osteitis by TCZ was observed at week 2, and continued improvement was observed through week 52. Erosion scores did not worsen in either group. These data provide evidence linking reductions in synovitis and osteitis via IL-6 receptor antagonism to a lack of progression of erosion as measured by MRI.

Individual joints in which osteitis was reduced were less likely to erode. This indicates that a reduction in osteitis may be part of the mechanistic basis for joint protection in patients treated

\begin{tabular}{|c|c|c|}
\hline $\begin{array}{l}\text { Predictors of MRI erosion change }>1.0 \text { at } \\
\text { week } 52 \text { (no. of erosion events } / \mathrm{n} ; 11 / 1096 \text { ) }\end{array}$ & OR $(95 \% \mathrm{Cl})$ & p Value \\
\hline \multicolumn{3}{|l|}{ Model 1} \\
\hline Baseline osteitis of matching joint & 2.10 (1.01 to 4.37 ) & 0.0467 \\
\hline Baseline synovitis of matching joint & 3.34 (1.99 to 5.62$)$ & $<0.0001$ \\
\hline $\begin{array}{l}\text { Osteitis worsening change at week } 12 \text { of } \\
\text { matching joint }\end{array}$ & 7.96 (3.07 to 20.68$)$ & $<0.0001$ \\
\hline $\begin{array}{l}\text { Synovitis worsening change at week } 12 \text { of } \\
\text { matching joint }\end{array}$ & 1.46 (0.32 to 6.78$)$ & 0.6278 \\
\hline \multicolumn{3}{|l|}{ Model 2} \\
\hline Baseline osteitis of matching joint & 2.13 (0.99 to 4.59$)$ & 0.0528 \\
\hline Baseline synovitis of matching joint & $2.76(1.75$ to 4.35$)$ & $<0.0001$ \\
\hline $\begin{array}{l}\text { Osteitis worsening change at week } 52 \text { of } \\
\text { matching joint }\end{array}$ & 4.43 (1.83 to 10.74$)$ & 0.0010 \\
\hline $\begin{array}{l}\text { Synovitis worsening change at week } 52 \text { of } \\
\text { matching joint }\end{array}$ & 1.01 (0.46 to 2.21 ) & 0.9769 \\
\hline
\end{tabular}

${ }^{*}$ Models are logistic regressions to evaluate joint-level MRI erosion progression at week 52 with listed predictors, adjusted for correlation of joints within patients. OR interpreted as the increased odds of erosion change $>1$ (ie, progression) at week 52 per 1 unit change in predictor, adjusting for the other effects. $p$ value $<0.05$ indicates statistically significant increased risk of erosion change (progression). with TCZ, as with other biologics. ${ }^{3} 2122$ Additional studies are needed to determine how a reduction in synovitis and osteitis affects other clinical outcomes, such as remission and lowdisease activity, in patients receiving TCZ as monotherapy or in combination with MTX.

Most studies with MRI outcomes have demonstrated similar patterns of response for synovitis and osteitis, although a 2 -week time point is unusual. Previous work has suggested that osteitis is related to severity of adjacent synovitis and that most likely represents a dependent and related process. ${ }^{23}$ Recent data from a randomised abatacept RA trial with a 4-month endpoint suggested a differential response between osteitis (measured at 23 sites within wrist and MCP joints) and synovitis (measured at three sites in the wrist), though this may have reflected the number of sites evaluated for each pathology and the consequential differential responsiveness of the measures. ${ }^{24}$ In the current study, it is interesting to note that one arm of the study demonstrated statistically significant improvements in synovitis (measured at seven sites) but not osteitis; however, this must be interpreted with caution in light of the small changes involved.

Previous studies in patients with RA, including LITHE and ACT-RAY, have shown prevention of radiographic joint damage at 52 weeks after treatment. ${ }^{13} 25$ These previous results have now been confirmed with the use of MRI; patients treated with

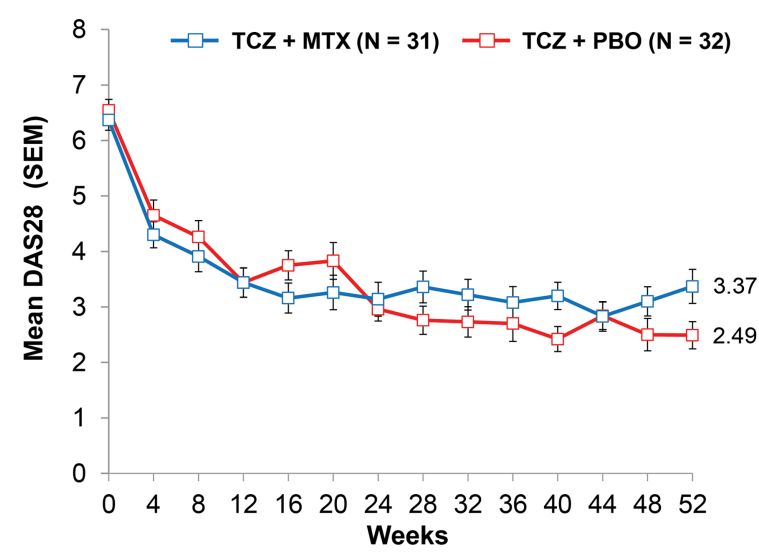

TCZ + MTX: $n=\begin{array}{llllllllllllll}31 & 31 & 29 & 31 & 27 & 28 & 27 & 28 & 27 & 26 & 28 & 25 & 26 & 23\end{array}$ TCZ + PBO: $n=\begin{array}{llllllllllllll}32 & 30 & 31 & 29 & 27 & 24 & 28 & 26 & 26 & 23 & 23 & 22 & 20 & 23\end{array}$

Figure 4 Disease Activity Score using 28 joints over 52 weeks. MTX, methotrexate; PBO, placebo; TCZ, tocilizumab. 
TCZ+MTX or TCZ+PBO had no statistically significant increase in mean RAMRIS erosion scores through week 52. MRI erosion scores at weeks 12 and 52 correlated with radiographic erosion scores at week 52. This finding is consistent with that of other studies, which observed that MRI is more sensitive at detecting such changes earlier than are X-rays at 52 weeks. $^{26-28}$

Although some numeric group differences in MRI results were observed (eg, larger synovitis improvements in the TCZ + PBO arm), they may still have been due to chance because of the relatively small sample size. No clear discrepancies in baseline characteristics, additional use of conventional DMARDs, adherence with infusions and MTX/PBO, steroid dose or concomitant use of other medications were observed. In general, the efficacy results observed in this substudy were consistent with those of the overall ACT-RAY study.

The mechanism by which TCZ improves the signs and symptoms of RA has not been fully elucidated. Although C-reactive protein has been used as a marker of inflammation, its use is complicated by the fact that TCZ inhibits IL- 6 signalling and consequently reduces C-reactive protein levels. ${ }^{29}$ Differentiating between a reduction in inflammation and the direct effects of the therapeutic agent makes it difficult to fully diagnose disease activity in patients. However, other indicators of inflammation, such as MRI and changes in proinflammatory $\mathrm{T}$ cell populations, have shown that TCZ significantly reduces inflammatory burden. ${ }^{30}$ In the current study, improvements in synovitis and osteitis scores were observed as early as 2 weeks and were sustained over 52 weeks. This indicates that MRI may be used successfully to detect changes in the status of bone and joint inflammation. This finding indicates that inhibition of IL- 6 function by TCZ can reduce inflammation at the bone and joint level.

This study had several limitations. First, no gadolinium enhancement was used, which may have decreased the specificity of synovitis evaluations. ${ }^{31}$ Second, MRI with a field strength of $0.2 \mathrm{~T}$ was used. Although most clinical trials using the RAMRIS scoring system have used MRI with a field strength of 1.5 T, low-field MRI in previous studies has demonstrated comparable specificity but lower sensitivity compared with high-field MRI. However, it has been demonstrated that $0.2 \mathrm{~T}$ MRI and 1.5 T MRI performed equivalently, both cross-sectionally and longitudinally. ${ }^{32} 33$ A lower sensitivity of $0.2 \mathrm{~T}$ MRI may nevertheless have resulted in underestimation of the antiinflammatory response or overestimation of the antierosive response to TCZ treatment in some patients. These differences in magnetic field strength and the lack of contrast enhancement also complicate comparisons of the results of this study with those of other studies. Additionally, the study lacked an inactive comparator arm, which would have helped confirm that the assessments were sensitive enough to reliably demonstrate nonprogression of bone erosion. It is worth noting, however, that all nine randomised controlled trials using MRI that were previously evaluated by the readers in this study consistently showed progression of bone erosion, ${ }^{4} 172433-38$ including one using 0.2 T MRI. $^{17} 33$

This study provided an independent measure of synovitis, osteitis and erosion through MRI and confirmed that treatment with TCZ reduces inflammation in patients with RA. A reduction in synovitis and osteitis through IL-6 receptor antagonism is one of the mechanisms by which TCZ protects joints in patients with RA.

Acknowledgements The authors wish to thank Andy Anisfeld for his scientific contributions and leadership on this project.
Contributors PGC, CP, EO, JK, DR, JD and OT were involved in generating the data at their clinical research sites and interpreting the data. JD and JF analysed and interpreted the data. All authors were involved in writing the manuscript and approved it.

Funding F. Hoffmann-La Roche, Ltd (Roche) funded and sponsored the study and participated in the design of the study, as well as in the collection, analysis and interpretation of the data. This manuscript was reviewed by Roche, but the decision to submit and publish this manuscript was contingent only on the approval of the lead author and coauthors, including those employed by Roche. Support for third-party writing assistance for this manuscript, furnished by Denise Kenski, PhD of Health Interactions, was provided by F. Hoffmann-La Roche, Ltd.

Competing interests PGC has participated in speakers bureaus for BMS, Janssen, Pfizer, Roche. EO received speaking fees and honoraria from Genentech. JK received consulting fees from Pfizer, BMS and UCB and speakers bureau fees from Pfizer and BMS. JF and JD are employees of Genentech. OT was granted research support from the ACT-RAY clinical trial.

\section{Patient consent Obtained.}

Ethics approval Appropriate institutional review boards/ethics committees.

Provenance and peer review Not commissioned; externally peer reviewed.

Open Access This is an Open Access article distributed in accordance with the Creative Commons Attribution Non Commercial (CC BY-NC 3.0) license, which permits others to distribute, remix, adapt, build upon this work non-commercially, and license their derivative works on different terms, provided the original work is properly cited and the use is non-commercial. See: http://creativecommons.org/ licenses/by-nc/3.0/

\section{REFERENCES}

1 Chen TS, Crues JV 3rd, Ali M, et al. Magnetic resonance imaging is more sensitive than radiographs in detecting change in size of erosions in rheumatoid arthritis. J Rheumatol 2006;33:1957-67.

2 McGonagle $D$, Conaghan PG, $O^{\prime}$ Connor $P$, et al. The relationship between synovitis and bone changes in early untreated rheumatoid arthritis: a controlled magnetic resonance imaging study. Arthritis Rheum 1999;42:1706-11.

3 Ostergaard M, Emery P, Conaghan PG, et al. Significant improvement in synovitis, osteitis, and bone erosion following golimumab and methotrexate combination therapy as compared with methotrexate alone: a magnetic resonance imaging study of 318 methotrexate-naive rheumatoid arthritis patients. Arthritis Rheum 2011;63:3712-22.

4 Cohen SB, Dore RK, Lane NE, et al. Denosumab treatment effects on structural damage, bone mineral density, and bone turnover in rheumatoid arthritis: a twelve-month, multicenter, randomized, double-blind, placebo-controlled, phase II clinical trial. Arthritis Rheum 2008;58:1299-309.

5 Dougados M, Devauchelle-Pensec V, Ferlet JF, et al. The ability of synovitis to predict structural damage in rheumatoid arthritis: a comparative study between clinical examination and ultrasound. Ann Rheum Dis 2013;72:665-71.

6 Aletaha D, Smolen JS. Joint damage in rheumatoid arthritis progresses in remission according to the disease activity score in 28 joints and is driven by residual swollen joints. Arthritis Rheum 2011;63:3702-11.

7 Gandjbakhch F, Conaghan PG, Ejbjerg B, et al. Synovitis and osteitis are very frequent in rheumatoid arthritis clinical remission: results from an MRI study of 294 patients in clinical remission or low disease activity state. J Rheumatol 2011;38:2039-44.

8 Ranganath VK, Strand V, Peterfy CG, et al. The utility of magnetic resonance imaging for assessing structural damage in randomized controlled trials in rheumatoid arthritis: report from the imaging group of the American College of Rheumatology RA clinical trials task force. Arthritis Rheum 2013;65:2513-23.

9 Peterfy C, Ostergaard M, Conaghan PG. MRI comes of age in RA clinical trials. Ann Rheum Dis 2013;72:794-6.

10 Emery P, Keystone E, Tony HP, et al. IL-6 receptor inhibition with tocilizumab improves treatment outcomes in patients with rheumatoid arthritis refractory to anti-tumour necrosis factor biologicals: results from a 24-week multicentre randomised placebo-controlled trial. Ann Rheum Dis 2008;67:1516-23.

11 Genovese MC, McKay JD, Nasonov EL, et al. Interleukin-6 receptor inhibition with tocilizumab reduces disease activity in rheumatoid arthritis with inadequate response to disease-modifying antirheumatic drugs: the tocilizumab in combination with traditional disease-modifying antirheumatic drug therapy study. Arthritis Rheum 2008;58:2968-80.

12 Smolen JS, Beaulieu A, Rubbert-Roth A, et al. Effect of interleukin-6 receptor inhibition with tocilizumab in patients with rheumatoid arthritis (OPTION study): a double-blind, placebo-controlled, randomised trial. Lancet 2008;371:987-97.

13 Kremer JM, Blanco $R$, Brzosko $M$, et al. Tocilizumab inhibits structural joint damage in rheumatoid arthritis patients with inadequate responses to methotrexate: results from the double-blind treatment phase of a randomized placebo-controlled trial of 
tocilizumab safety and prevention of structural joint damage at one year. Arthritis Rheum 2011;63:609-21.

14 Jones $\mathrm{G}$, Sebba $\mathrm{A}$, Gu J, et al. Comparison of tocilizumab monotherapy versus methotrexate monotherapy in patients with moderate to severe rheumatoid arthritis: the AMBITION study. Ann Rheum Dis 2010;69:88-96.

15 Dougados M, Kissel K, Conaghan PG, et al. Clinical, radiographic, and immunological effects after 1 year of tocilizumab-based treatment strategies in rheumatoid arthritis: the ACT-RAY study. Ann Rheum Dis 2014;73: 803-9.

16 Dougados M, Kissel K, Sheeran T, et al. Adding tocilizumab or switching to tocilizumab monotherapy in methotrexate inadequate responders: 24-week symptomatic and structural results of a 2-year randomised controlled strategy trial in rheumatoid arthritis (ACT-RAY). Ann Rheum Dis 2013;72:43-50.

17 Peterfy CG, Olech E, DiCarlo JC, et al. Monitoring cartilage loss in the hands and wrists in rheumatoid arthritis with magnetic resonance imaging in a multi-center clinical trial: IMPRESS (NCT00425932). Arthritis Res Ther 2013;15:R44.

18 Peterfy C, Troum O, Olech E, et al. Discriminative power of different combinations of bones and joints for assessing change in rheumatoid arthritis with low-field MRI. Ann Rheum Dis 2010;69:119.

19 Quinn MA, Conaghan PG, O'Connor PJ, et al. Very early treatment with infliximab in addition to methotrexate in early, poor-prognosis rheumatoid arthritis reduces magnetic resonance imaging evidence of synovitis and damage, with sustained benefit after infliximab withdrawal: results from a twelve-month randomized, double-blind, placebo-controlled trial. Arthritis Rheum 2005;52:27-35.

20 Bruynesteyn $\mathrm{K}$, Boers $\mathrm{M}$, Kostense $\mathrm{P}$, et al. Deciding on progression of joint damage in paired films of individual patients: Smallest detectable difference or change. Ann Rheum Dis 2005:64:179-82.

21 Conaghan PG, Emery P, Ostergaard M, et al. Assessment by MRI of inflammation and damage in rheumatoid arthritis patients with methotrexate inadequate response receiving golimumab: results of the GO-FORWARD trial. Ann Rheum Dis 2011;70:1968-74.

22 Durez P, Malghem J, Nzeusseu Toukap A, et al. Treatment of early rheumatoid arthritis: a randomized magnetic resonance imaging study comparing the effects of methotrexate alone, methotrexate in combination with infliximab, and methotrexate in combination with intravenous pulse methylprednisolone. Arthritis Rheum 2007:56:3919-27.

23 Conaghan PG, O'Connor P, McGonagle D, et al. Elucidation of the relationship between synovitis and bone damage: a randomized magnetic resonance imaging study of individual joints in patients with early rheumatoid arthritis. Arthritis Rheum 2003:48:64-71.

24 Conaghan PG, Durez P, Alten RE, et al. Impact of intravenous abatacept on synovitis, osteitis and structural damage in patients with rheumatoid arthritis and an inadequate response to methotrexate: the ASSET randomised controlled trial. Ann Rheum Dis 2013;72:1287-94.

25 Dougados M, Kissel K, Conaghan PG, et al. Clinical, radiographic, and immunogenic effects after 1 year of tocilizumab-based treatment strategy with and without methotrexate in rheumatoid arthritis: the ACT-RAY study. Arthritis Rheum 2012;64:2550.

26 Ostergaard M, Pedersen SJ, Dohn UM. Imaging in rheumatoid arthritis—status and recent advances for magnetic resonance imaging, ultrasonography, computed tomography and conventional radiography. Best Pract Res Clin Rheumatol 2008:22:1019-44.

27 Hoving JL, Buchbinder R, Hall S, et al. A comparison of magnetic resonance imaging, sonography, and radiography of the hand in patients with early rheumatoid arthritis. J Rheumatol 2004;31:663-75.

28 Klarlund $\mathrm{M}$, Ostergaard $\mathrm{M}$, Jensen $\mathrm{KE}$, et al. Magnetic resonance imaging, radiography, and scintigraphy of the finger joints: one year follow up of patients with early arthritis. The TIRA Group. Ann Rheum Dis 2000;59:521-8.

29 Choy E. Understanding the dynamics: pathways involved in the pathogenesis of rheumatoid arthritis. Rheumatology (Oxford) 2012;51(Suppl 5):v3-11.

30 Samson M, Audia S, Janikashvili N, et al. Brief report: Inhibition of interleukin-6 function corrects Th17/treg cell imbalance in patients with rheumatoid arthritis. Arthritis Rheum 2012;64:2499-503.

31 Ostergaard $\mathrm{M}$, Conaghan $\mathrm{PG}, \mathrm{O}^{\prime}$ Connor $\mathrm{P}$, et al. Reducing invasiveness, duration, and cost of magnetic resonance imaging in rheumatoid arthritis by omitting intravenous contrast injection -- does it change the assessment of inflammatory and destructive joint changes by the OMERACT RAMRIS? I Rheumatol 2009;36:1806-10.

32 Taouli B, Zaim S, Peterfy CG, et al. Rheumatoid arthritis of the hand and wrist: Comparison of three imaging techniques. AJR Am J Roentgenol 2004;182:937-43.

33 Peterfy C, Olech E, Gaylis N, et al. Comparison of 1.5 T whole-body MRI and 0.2 T extremity MRI for monitoring rheumatoid arthritis in a multi-site clinical trial (IMPRESS). Ann Rheum Dis 2011;70:368.

34 Genovese MC, Kavanaugh A, Weinblatt ME, et al. An oral syk kinase inhibitor in the treatment of rheumatoid arthritis: A three-month randomized, placebo-controlled, phase II study in patients with active rheumatoid arthritis that did not respond to biologic agents. Arthritis Rheum 2011;63:337-45.

35 Peterfy C, Haraoui B, Kavanaugh A, et al. Baseline levels of the inflammatory biomarker $\mathrm{C}$-reactive protein are significantly correlated with magnetic resonance imaging measures of synovitis at baseline and after 26 weeks of treatment in patients with early rheumatoid arthritis. Arthritis Rheum 2011;63:1612.

36 Peterfy C, Emery P, Tak PP, et al. Rituximab (RTX) plus methotrexate (MTX) prevents bone erosion and joint-space narrowing (JSN) and reduces synovitis, osteitis as shown on MRI: results from a randomised, placebo-controlled trial in patients (pts) with rheumatoid arthritis (RA-SCORE). Ann Rheum Dis 2011;70:152.

37 Peterfy CG, Emery P, Genovese MC, et al. Magnetic resonance imaging substudy in a phase $2 \mathrm{~b}$ dose-ranging study of baricitinib, an oral Janus kinase 1 /Janus kinase 2 inhibitor, in combination with traditional disease-modifying antirheumatic drugs in patients with rheumatoid arthritis. Arthritis Rheum 2012;64:2488.

38 Beals C, Baumgartner R, Peterfy C, et al. Treatment effects measured by dynamic contrast enhanced MRI and RAMRIS for rheumatoid arthritis. Ann Rheum Dis 2013;72:748 